\title{
A rare case: a lung cancer with maxillary metastasis
}

\author{
Gulmez $A^{1 *}$, Gulbas $\mathrm{H}^{2}$, Ozcan $\mathrm{M}^{3}$ and Elkiran $\mathrm{ET}^{1}$ \\ ${ }^{1}$ Turgut Ozal Medical Center Oncology Department, Malatya, Türkiye \\ ${ }^{2}$ Turgut Ozal Medical Center Radiation Oncology Department, Malatya, Türkiye \\ ${ }^{3}$ Turgut Ozal Medical Center Pathology Department, Malatya, Türkiye
}

\begin{abstract}
Lung cancer is a serious health problem for the whole world in terms of morbidity and mortality. Lung cancers are divided into two main groups: small cell lung cancer and non-small cell lung cancer. Lung cancer can present with visceral organ metastasis and/or bone metastasis at the time of diagnosis. Maxillar metastasis is extremely rare in lung cancer as in other malignant tumors. In this case, we will discuss the maxillar metastasis of lung squamous cancer.
\end{abstract}

\section{Introduction}

Lung cancer is the most common cause of cancer-related deaths in both sexes [1]. Squamous cell carcinoma (SCC) accounts for approximately $30 \%$ of all non-small cell carcinomas in the lung [2]. Squamous cell lung cancer is generally a disease that tends to be limited to thorax rather than metastatic [3-5]. Bone metastasis is detected in $30 \%$ of patients with lung cancer. This leads to significant morbidity and mortality [6].

The metastasis of patients with lung SCC to the maxillar area is extremely rare. We report a case of lung cancer with maxillar metastasis at the time of diagnosis. We hope that it will contribute to the literature.

\section{Case report}

A 75-year-old male patient was admitted to the hospital with complaints of cough and shortness of breath 2 months ago. Diabetes Mellitus (DM) and hypertension (HT) are present in the patient's history. They are under treatment and stable in terms of these diseases. The patient has a smoking history of 60 packs/year and is still an active smoker. No alcohol use. In the chest X-ray taken after physical examination; the left lung mass and pleural effusion on the same side was detected. A bronchoscopic biopsy was planned after thorax tomography. The pathological examination of the bronchoscopic biopsy revealed lung squamous cell carcinoma. PET / CT for metastasis screening was also performed; A mass of $47 \times 68 \mathrm{~mm}$ (SUD max 9.9) was detected in the right maxilla. In addition, right supraclavicular, left supraclavicular and bilateral multiple nodes with SUD max in mediastinum were detected. The primary lesion of the patient; In the left hilar region, it was determined as $51 \times 84 \mathrm{~mm}$ (SUD max 9.1). In addition, a lesion (SUD max 4,5) was detected in liver segment 4 . Also, increased metabolic activity was detected in the left hand 1. Finger distal phalanx (SUD max 7,3), in the left acetabular region and ischium pubis in the pelvis (SUD max 10,5).

The patient was treated as a metastatic disease with his current condition. The patient had pain due to skeletal metastases. Palliative radiotherapy was planned for the pain related to the metastases in the pelvis. A diagnostic biopsy was planned for the lesion in the maxillary region of the patient. The biopsy of the maxillary region revealed squamous cell carcinoma. The patient was planned to undergo a diagnostic biopsy because of increased metabolic activity in the left-hand phalanx and the finger swollen and painful on physical examination. However, due to technical insufficiency could not be received. Systemic treatment was decided after palliative radiotherapy.

\section{Discussion}

Bone metastases of lung cancer are well known. However, maxillar metastasis is extremely rare. In a previous study; Meyer and Shklar reviewed 2400 oral malignancies over a 12 -years period. Only 25 metastatic tumors were found. This figure represents $1 \%$ of oral malignancies. In the same study, bone metastasis was detected in 70$85 \%$ of metastatic patients who died from breast, prostate and lung cancer. Only $1 \%$ of these patients have maxillar metastasis [7] (Figures $1-4)$.

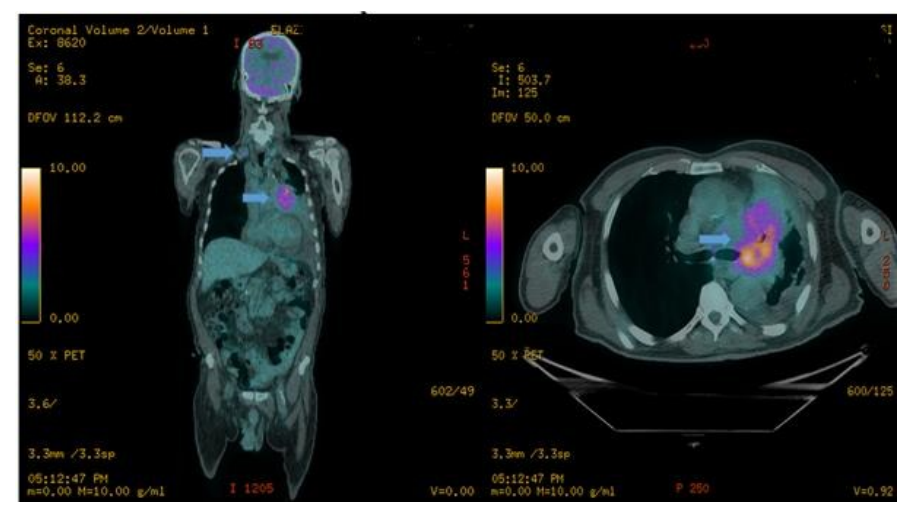

Figure 1. PET / CT image of the primary lesion in the lung of the patient

${ }^{\star}$ Correspondence to: Ahmet Gulmez, Turgut Ozal Medical Center Oncology Department, Malatya, Türkiye, E-mail: doktor.ahmetgulmez@gmail.com

Key words: lung cancer, maxillary metastasis, bone metastasis

Received: January 26, 2020; Accepted: February 04, 2020; Published: February 10,2020 


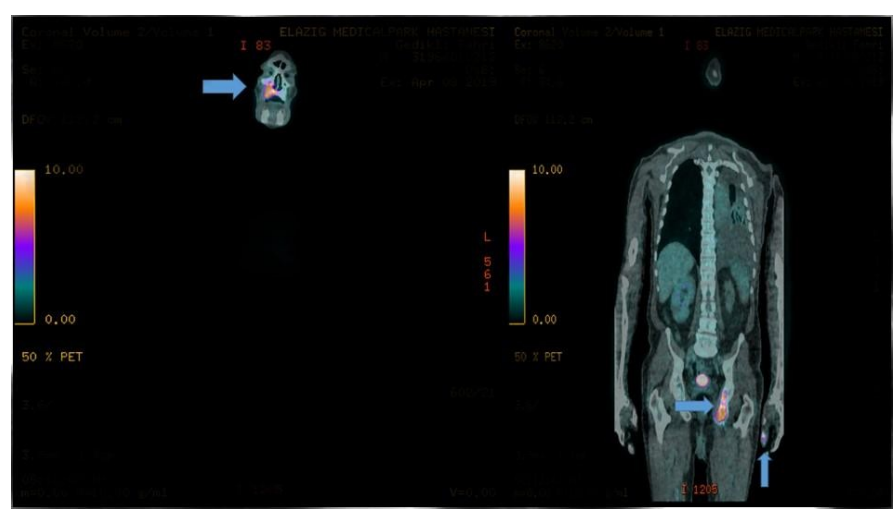

Figure 2. Metastasis of the patient in the maxillary region and metastatic lesion in the ischium pubis, left-hand 1st phalanx

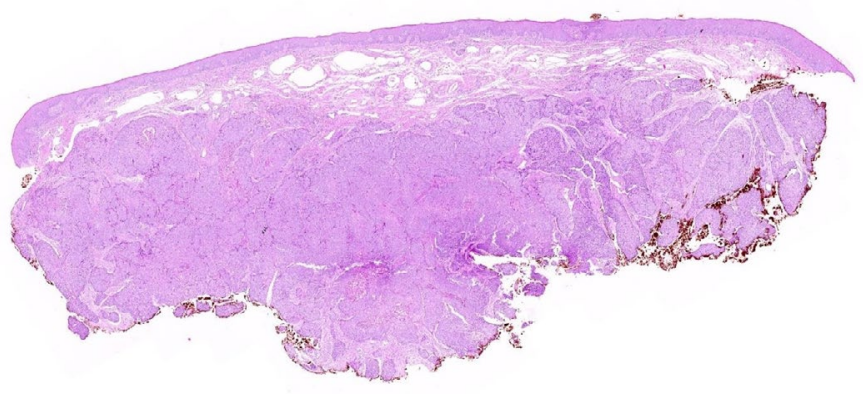

$500 \mu \mathrm{m}$

Figure 3. Tumor islands unrelated to the surface epithelium.

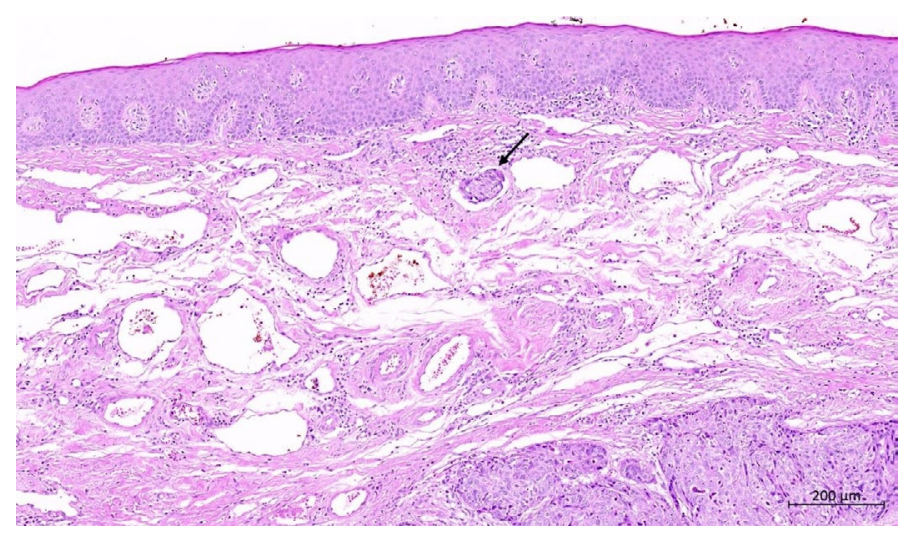

Figure 4. Tumor thrombus is seen in the lymphatic below the surface epithelium.

In another study; Jaw metastases are more common in women than men. The posterior mandible is the most common site and the average age is 55.6 years [8].

In other studies, researchers reported that the most common malignancies that metastasize to the oral cavity were lung, breast, kidney, prostate, thyroid and gastric cancers [9-11]. Some researchers describe lung cancer as the most common metastasis to the oral cavity $[12,13]$.
Metastasis to the oral cavity is a sign of extensive metastasis, often showing a fatal outcome shortly after diagnosis of oral metastasis $[11,14]$. In a study by Adebayo and Ajike, 19 of 24 (79\%) patients with oral metastatic tumors died within 1 year from the time of diagnosis. Oral metastasis was shown to be a sign of poor prognosis [15].

Oral cavity metastases of previously reported lung cancer are usually seen in the adenocancer type. It is generally reported that oral cavity metastases develop during the clinical course. In our case, we present a maxillary metastasis due to lung squamous cell carcinoma and It was diagnosed at the same time as a primary disease. The maxillary lesion of the patient was large enough to suggest a secondary primer. Biopsy from the maxillary mass of the patient was reported as squamous cell carcinoma. In patients with lung cancer; A biopsy of the lesion should be considered in the presence of an oral lesion detected by the doctor or patient. Although extremely rare; it should be kept in mind that maxillary and mandibular metastasis may be present in patients with diffuse metastatic lung cancer.

\section{References}

1. Greenlee RT, Hill-Harmon MB, Murray T, Thun M (2001) Cancer statistics, 2001. $C A$ Cancer J Clin 51: 15-36. [Crossref]

2. Nonaka D (2012) A study of $\triangle \mathrm{Np} 63$ expression in lung non-small cell carcinomas. $\mathrm{Am}$ J Surg Pathol 36: 895-899. [Crossref]

3. Strauss B, Weller CV (1957) Bronchogenic carcinoma; statistical analysis of two hundred ninety- six cases with necropsy as to relationships between cell types and age, sex, and metastasis. AMA Arch Pathol 63: 602-611.

4. Mountain CF, Lukeman JM, Hammar SP (1987) Lung cancer classification: the relationship of disease extent and cell type to survival in a clinical trials population. $J$ Surg Oncol 35: 147-156.

5. Hansen HH, Muggia FM (1972) Staging of inoperable patients with bronchogenic carcinoma with special reference to bone marrow examination and peritoneoscopy. Cancer 30: 1395-1401.

6. Yasar F, Oz G, Dolanmaz D, Akgünlü F (2006) Mandibular metastasis in a patient with pulmonary adenocarcinoma. Dentomaxillofac Radiol 35: 383-385.

7. Meyer I, Shklar G (1965) Malignant tumors metastatic to mouth and jaws. Oral Surg Oral Med Oral Pathol 20: 350-362. [Crossref]

8. Clausen F, Poulsen H (1963) Metastatic carcinoma to the jaws. Acta Pathol Microbiol Scand

9. Hirshberg A, Buchner A (1995) Metastatic tumours to the oral region. An overview. Eur $J$ Cancer B Oral Oncol 31: 355-360

10. Rodado C, Gonzalez J, Huguet P, Avila M, Raspall G (2019) Lung adenocarcinoma presenting as an oral metastasis. Med Oral 2: 315-320.

11. Nishimura Y, Yakata H, Kawasaki T, Nakajima T (1982) Metastatic tumours of the mouth and jaws. A review of the Japanese literature. J Maxillofac Surg 10: 253-258.

12. Zachariades N (1989) Neoplasms metastatic to the mouth, jaws and surrounding tissues. J Craniomaxillofac Surg 17: 283-290.

13. Pires FR, Sagarra R, Corrêa ME, Pereira CM, Vargas PA, et al. (2004) Oral metastasis of a hepatocellular carcinoma. Oral Surg Oral Med Oral Pathol Oral Radiol Endod 97: 359-368. [Crossref]

14. Hirshberg A, Leibovich P, Buchner A (1994) Metastatic tumors to the jawbones: analysis of 390 cases. J Oral Pathol Med 23: 337-341.

15. Adebayo E, Ajike S (2011) Report of six cases of metastatic jaw tumours in Nigerians. Niger J Surg Res 6: 1-2.

Copyright: (C2020 Gulmez A. This is an open-access article distributed under the terms of the Creative Commons Attribution License, which permits unrestricted use, distribution, and reproduction in any medium, provided the original author and source are credited. 